\title{
Predictors of condom use behavior among men who have sex with men in China using a modified information-motivation- behavioral skills (IMB) model
}

\author{
Hongbo Jiang ${ }^{1+}$, Xiaobin Chen ${ }^{1+}$, Jing $\mathrm{Li}^{1}$, Zhimin Tan ${ }^{1}$, Weibin Cheng ${ }^{2^{*}}$ and Yi Yang ${ }^{1 *}$ (1)
}

\begin{abstract}
Background: Men who have sex with men (MSM) are at high risk for human immunodeficiency virus (HIV) infection in China. Correct and consistent condom use is one of the most effective strategies for preventing the spread of HIV. This study developed a modified Information-Motivation-Behavioral Skills (IMB) model to predict condom use behavior among Chinese MSM.

Methods: A cross-sectional study was conducted to collect data using self-administered electronic questionnaire. Participants were recruited from HIV Voluntary Counseling and Testing clinics in six district Centers for Disease Control and Prevention in Guangzhou and two community-based HIV service centers (Lingnan Partners and Zhitong Charity) from May to September 2017. Structural equation modeling was performed to develop the modified IMB model with extended multilevel factors.

Results: Among the 976 MSM included, 52.05\% had engaged in anal intercourse with a condom every time. The final modified IMB model fitted the data more ideally than the conventional model. The final modified IMB model revealed that behavioral skills positively contributed directly to condom use $(\beta=0.385, p<0.001)$ and partially mediated the associations between information $(\beta=0.106, p=0.005)$ and motivation $(\beta=0.390, p<0.001)$ and condom use. Regarding the extended multilevel factors, education, income, receiving HIV prevention services, sexual partner seeking behavior, depression, intimate partner violence, and child sexual abuse had indirect impacts on condom use that were mediated by information, motivation, and/or behavioral skills $(p<0.05)$. All paths from the latent variable to the corresponding observed variables were statistically significant $(p<0.001)$.

Conclusion: The modified IMB model with extended multilevel factors could serve as a theoretical framework for behavioral interventions for condom use among Chinese MSM. Further prospective studies are needed to examine the predictive power of the modified IMB model.
\end{abstract}

Keywords: Men who have sex with men, Condom use, HIV, Information-motivation-behavioral skills model, Multilevel factors

\footnotetext{
*Correspondence: bin_cheng817@163.com; yangyigz@163.com

${ }^{\dagger}$ Hongbo Jiang and Xiaobin Chen contributed equally to this work.

${ }^{2}$ Department of AIDS/STD Control and Prevention, Guangzhou Center for

Disease Control and Prevention, No. 1 Qide Road, Baiyun District,

Guangzhou, China

'Department of Epidemiology and Biostatistics, School of Public Health,

Guangdong Pharmaceutical University, No. 283 Jianghai Road, Haizhu

District, Guangzhou, China
}

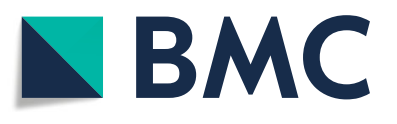

(c) The Author(s). 2019 Open Access This article is distributed under the terms of the Creative Commons Attribution 4.0 International License (http://creativecommons.org/licenses/by/4.0/), which permits unrestricted use, distribution, and reproduction in any medium, provided you give appropriate credit to the original author(s) and the source, provide a link to the Creative Commons license, and indicate if changes were made. The Creative Commons Public Domain Dedication waiver (http://creativecommons.org/publicdomain/zero/1.0/) applies to the data made available in this article, unless otherwise stated. 


\section{Background}

Antiretroviral therapy (ART) has greatly reduced HIV-related mortality since 1996. While human immunodeficiency virus (HIV) infection/acquired immune deficiency syndrome (AIDS) remains a leading cause of death and a disease burden in many countries and regions [1]. Men who have sex with men (MSM) continue to have disproportionately high burdens of HIV infection in countries of low-, middle-, and high-income [2]. Notification of HIV cases among MSM in China rose from $2.5 \%$ in 2006 to $25.8 \%$ in 2014 [3]. The results of a multisite cross-sectional study reported high HIV prevalence of $9.9 \%$ among MSM in China [4]. Unprotected anal intercourse (UAI) is a common high-risk behavior and reason for HIV infection among MSM [5]. Evidence from a recent meta-analysis showed that the proportion of UAI with any male partner among MSM in China was 53\% (95\% confidence interval [CI]: 51-56\%) [6]. One serial cross-sectional study presented that the proportion of UAI was 58.4\% during the last 6 months among MSM in Guangzhou [7]. Correct and consistent condom use, is one of the most effective strategies for preventing the spread of HIV among general and high-risk populations [8]. Strengthening this behavior among MSM in China is thus an important issue for research.

Evidence shows that new public health and/or health-promotion interventions based on social and behavioral science theories are more effective than those lacking a theoretical framework [9], this is because these interventions are tailored towards addressing the identified predictors of the health behavior of interest. Specifically, the Information-Motivation-Behavioral Skills (IMB) model has been found to significantly predict condom use among MSM [10], female sex workers [11], people attending sexually transmitted infection (STI) clinics [12], and students [13]. Consequently, interventions designed along IMB constructs have been found to increase condom use among MSM [14], HIV-infected patients [15], and students [16]. The IMB model proposes that information, motivation, and behavioral skills are fundamental determinants of HIV-preventive behaviors, e.g. condom use [17]. According to the model, possession of adequate information coupled with a strong motivation to act on the information propels the desired behavioral skills, which in turn initiate and sustain condom use. The behavioral skills that directly influence condom use also partially mediate the associations between information/motivation and condom use [17-19].

Although the components of the IMB model influence one another, studying them in isolation from other social influences of behavior yields less predictive power [20]. The IMB model in its non-extended form relies only on psychological or individual-level influences, whereas social factors have a significant influence on behaviors [20,21]. Meta-analyses of behavioral intervention show that individual-level theories cannot explain the heterogeneity among study outcomes [22]. Thus, researchers have suggested extending the model by incorporating other social factors that influence preventive behaviors [20,21]. Modified IMB models with extended constructs have been found to explain more variance in HIV-preventive behavior than the original non-extended model [20, 21, 23, 24]. However, existing literature has insufficiently integrated these social factors and explored their interactions [25]. Recent efforts have been made to expand from individual-level factors to multilevel factors at different ecological levels. The multiple domain model (MDM) suggests that factors outside of the individual are modeled as factors shaping one's behavior; these factors including structural factors, personality, and social environment situational/contextual variables [26]. The network-individual-resource model (NIRM) proposes that individual behavior changes for HIV prevention can be supported and sustained by the tangible and mental resources possessed by individuals and networks and that the outcomes may be resilient over time and disseminated more broadly [27]. The dynamic social systems model (DSSM) focuses on the structures that people face through interactions at the micro-, meso-, and macro-levels [28]. The Transmission Reduction Intervention Project (TRIP) suggests that HIV prevention can be greatly improved by using social science as an integrative tool in transdisciplinary research and practice [29]. Another review recommended a multilevel approach to HIV-related behavior changes, which suggested that the HIV risk and AIDS care involve complex behaviors beyond individual-level factors that are influenced by multilevel factors [30]. These multilevel factors include individual-level factors, interpersonal/network-level factors, and structural-level factors. Among the individual-level factors, income, education and depression were found to be associated with condom use [23, 31, 32], and these factors were integrated into a modified IMB model $[20,23]$. The interpersonal/network-level factors such as child sexual abuse (CSA) and intimate partner violence (IPV) tended to co-occur and increased the risk of UAI together with depression [32-34]. With use of Internet and mobile applications, an increasing number of MSM seek sexual partners online. Sexual partner seeking behavior, which is another interpersonal/network-level factor, may also impact condom use behavior [35]. Moreover, structural-level factors, such as access to HIV prevention and care services, may also have a positive effect on condom use [36]. However, the original IMB model has no role for interpersonal/ network-level or structural-level factors. Thus, an extension of the IMB model with interpersonal/network-level, structural-level, and more individual-level factors may be meaningful for improvement of the predictive power for the condom use behavior.

However, less is known about the application of modified IMB models for predicting condom use among MSM in China. Based on the high proportion of UAI $[6,7]$, 
increasing HIV prevalence [3, 4], and lack of evidence for the influence of the modified IMB model among MSM in China, we conducted this cross-sectional study to integrate the multilevel factors into the conventional IMB model and built a modified IMB model for predicting the condom use among MSM in China. The aim of this study is to provide a theoretical framework for safe sex behavioral intervention.

\section{Methods}

\section{Participants}

MSM were recruited from the HIV Voluntary Counseling and Testing (VCT) clinics of six district Centers for Disease Control and Prevention (CDCs) in Guangzhou (Baiyun, Conghua, Panyu, Huadu, Huangpu, and Zengcheng District), and two community-based HIV service centers (Lingnan Partners in Tianhe and Zhitong Charity in Yuexiu District) from May to September 2017 using a convenience sampling method. The inclusion criteria were as follows: (1) male aged 18 years and above, (2) had anal/oral intercourse with a man within the past 12 months, and (3) lived in Guangzhou for more than 3 months. Individuals who had obvious psychological or mental illnesses, dysnoesia, a foreign nationality, or refused to participate in the study were excluded. Individuals with debilitating illnesses and hearing or visual impairment were also excluded. The sample size was calculated using the formula $\left[\mathrm{N}=\mathrm{Z}_{\alpha}^{2} \mathrm{P}(1-\mathrm{P}) / \mathrm{d}^{2} \times\right.$ deff $]$. With a proportion of consistent condom use among MSM in Guangzhou $(P)$ of $41.6 \%$ [7], precision error $(d)$ of $0.1 P, 95 \%$ confidence level, and design effect (deff) of 1.5 due to non-probability sampling [37], the minimum sample size required for this study was calculated to be 890 after taking a non-response rate of $10 \%$ into consideration. MSM who met the inclusion criteria filled out the electronic questionnaire (Additional file 1). After completing the questionnaire, the participants underwent HIV consultations and testing. They also received a gift (condoms and personal lubricants) as compensation for their time. A total of 1174 MSM completed the survey during the study period, but the analysis was based on 976 who reported having anal intercourse within the past 6 months.

\section{Measures}

\section{Demographics and sexual characteristics}

Information was collected on age, birthplace, duration in Guangzhou, marital status, education, monthly income, occupation, sexual orientation, sexual role, and sexual partner seeking behaviors.

\section{HIV prevention services}

Three questions were used to assess whether the participants had received HIV prevention services within the last year. Such services include (1) condom promotion and distribution or HIV voluntary counseling and testing, (2) community-based methadone maintenance treatment or cleaning needle provided or exchanged, and (3) peer education for HIV prevention. Responses with "Yes" to any of these questions indicated receiving the HIV prevention services.

\section{Depression}

Depression was assessed using the Zung self-rating depression scale (SDS) [38]. The SDS index is derived by dividing the sum of the raw scores obtained on the 20 items by the maximum possible score of 80 and is expressed as a decimal point. An SDS index of 0.5 or above indicates depression (Cronbach's $\alpha=0.80$ ).

\section{CSA}

CSA was assessed with the following four questions: (1) "Did you have any sexual experiences (someone exposed his genitals or masturbated in front of you or attempted to have or had oral or anal sex with you) before 12 years of age?" (2) "Was the person you had the sexual experience with an adult or someone at least 5 years older than you?"; (3) "Between 12 and 16 years of age, did you have any unwanted sexual experiences?"; and (4) "Between 12 and 16 years of age, did you have any sexual experiences (wanted or unwanted) with an adult or someone who was at least 5 years older than you?" [33]. Responses with "Yes" to any of these questions indicated a CSA experience.

\section{IPV}

IPV was measured as ever experiencing an intimate partner who (1) "threatened to stop helping you with money or housing"; (2) "damaged or destroyed your property"; (3) "threatened to tell others about your sexual orientation"; (4) "verbally threatened to physically harm someone you cared for"; (5) "verbally threatened to harm you physically or emotionally"; (6) "hit you or threw something at you"; or (7) "forced you to have unwanted sex" [34]. Participants who responded with "Yes" to any of these questions were defined as a victim of IPV.

\section{Information}

Eight questions about general awareness of HIV/AIDS were used to assess prevention behavior (condom use) information among Chinese MSM under the guideline of the national AIDS sentinel surveillance program: (1) "Is AIDS an incurable serious infectious disease?"; (2) "Are MSM the most serious victims of AIDS in China?"; (3) "May a person who looks healthy carry HIV?"; (4) "Will infection with other sexually transmitted diseases increase the risk of HIV infection?"; (5) "Can correct condom use reduce the risk of HIV infection and transmission?"; (6) "Will the use of new drugs (methamphetamine, ecstasy, ketamine, etc.) increase the risk of HIV infection?"; (7) "Should HIV consultation and testing be actively sought after high-risk behaviors 
(needle-sharing drug abuse/unsafe sex, etc.)?"; (8) "Does deliberately spreading AIDS bear legal liability?". These questions were correctly answered as "Yes", but wrongly answered or unknown as "No" (Cronbach's $\alpha=0.57$ ). Individuals answering six or more questions correctly were defined as having adequate HIV-related knowledge [39].

\section{Motivation}

The motivation construct was measured using questions that assessed personal attitudes towards condom use, subjective norms and behavioral intentions regarding condom use $[17,18]$. Personal attitudes towards condom use were assessed by four items (e.g., "Discussion with my sexual partner about safe sex before sexual intercourse during the next month would be...") adapted from published scales using a 5-point Likert scale ranging from 1 (negative evaluation) to 5 (positive evaluation). A composite score was obtained by summing the responses to the four items, with higher scores indicating more positive personal attitudes towards condom use (Cronbach's $\alpha=0.96$ ).

Subjective norms regarding condom use were assessed by four items (e.g., "Most people who are important to me think I should discuss safe sex with a sexual partner before sexual intercourse during the next month") using a 5-point Likert scale ranging from 1 (negative evaluation) to 5 (positive evaluation). A composite score was obtained by summing the responses to the four items, with higher scores indicating more positive subjective norms regarding condom use (Cronbach's $\alpha=0.96$ ).

Behavioral intentions regarding condom use were assessed by four items (e.g., "If I have sex during the next month, I intend to discuss safe sex with a sexual partner before sexual intercourse") using a 5-point Likert scale ranging from 1 (negative evaluation) to 5 (positive evaluation). A composite score was obtained by summing the responses to the four items, with higher scores indicating more positive behavioral intentions regarding condom use (Cronbach's $\alpha=0.96$ ).

Personal attitudes towards condom use, subjective norms and behavioral intentions regarding condom use comprised the latent construct of the motivation to adopt HIV-preventive behaviors (Cronbach's $\alpha=0.96$ ).

\section{Behavioral skills}

The behavioral skills comprised the perceived difficulty and perceived effectiveness of HIV-preventive behaviors [17, 18].

The perceived difficulty of AIDS preventive behaviors was assessed by six items (e.g., "How hard would it be for you to buy condoms") using a 5-point Likert scale ranging from 1 (very hard) to 5 (very easy). A composite score was obtained by summing the responses to the six items, with higher scores indicating easier adoption of HIV-preventive behaviors (Cronbach's $\alpha=0.78$ ).

The perceived effectiveness of AIDS preventive behaviors was assessed by five items (e.g., "How effectively could you discuss safe sex with a sexual partner before sexual intercourse") using a 5-point Likert scale ranging from 1 (very ineffectively) to 5 (very effectively). A composite score was obtained by summing the responses to the five items, with higher scores indicating more effective adoption of HIVpreventive behaviors (Cronbach's $\alpha=0.95$ ).

Perceived difficulty and perceived effectiveness comprised the latent construct of the behavioral skills associated with HIV-preventive behaviors (Cronbach's $\alpha=0.73$ ).

\section{Condom use}

The participants were asked how often they had used condoms during anal sex over the past 6 months using a 5 -point Likert scale ranging from 1 (never) to 5 (always). A higher score indicated stronger commitment to HIV-preventive behaviors. Response with 5 (always) was defined as consistent condom use.

\section{Statistical analysis}

The data were abstracted from the electronic questionnaire platform. After data checking, frequencies and percentage were used to present categorical characteristics, and means (M) and standard deviations (SDs) were used for continuous characteristics of the participants. Pearson's correlation analysis was conducted to examine the correlations between the components of the modified IMB model with extended associated factors [20]. Structural equation modeling was performed to construct conventional and modified IMB models using a weighted least squares (WLS) estimator [40]. Model fit was assessed using the $\chi^{2}$ and degree of freedom ratio $\left(\mathrm{x}^{2} / d f\right.$ ratio), root mean square error of approximation (RMSEA), goodness of fit index (GFI), and adjusted goodness of fit index (AGFI) [41-43]. A good fit was indicated when the $\chi^{2} / d f$ ratio $\leq 3$ and RMSEA $\leq 0.05$ [41]. The GFI and AGFI were used to explain variance and were considered acceptable when the values were $\geq 0.90$ [42]. The data analyses were performed using SAS Version 9.4 (SAS Institute Inc., Cary, NC, USA). All hypothesis tests were 2-tailed with $\alpha=0.05$.

\section{Results \\ Social, sexual and psychological characteristics of the participants}

In total, $976 \mathrm{MSM}$ who had anal intercourse during the past 6 months were included in the current study. The mean age was $28.35 \pm 6.83$ years with a range from 18 to 67 years. Approximately half $(50.61 \%)$ of the participants were recruited from Lingnan Partners, 31.35\% from Zhitong Charity, and $18.03 \%$ from the six selected VCT clinics. The majority of the MSM participants had lived in Guangzhou for more than 12 months (88.52\%) and were college educated or above (75.31\%), unmarried (86.99\%), and employed (79.61\%). Approximately one-third of the participants were residents of Guangzhou (35.66\%), followed by residents of other cities in 
Guangdong Province (33.50\%), and of other provinces (30.84\%). Approximately half $(50.10 \%)$ of the participants earned more than 5000 Yuan (equivalent to U.S. \$725) per month.

Among the 976 participants, $74.08 \%$ identified themselves homosexual. Regarding the anal sex role, 157 $(16.09 \%)$ reported themselves as undertaking the insertive anal sex role with their male partners, 158 (16.19\%) reported themselves as undertaking the receptive anal sex role, and the rest $(67.73 \%)$ were versatile. Most $(89.96 \%)$ of the participants sought homosexual partners on the Internet. Approximately two-thirds (63.83\%) of the participants received HIV prevention services within the last year. The proportions of participants who reported consistent condom use, CSA, IPV, and depression were 52.05, $26.95,13.22$, and $43.24 \%$, respectively (Table 1 ).

\section{Information, motivation, and behavioral skills}

The mean HIV knowledge score was $6.59 \pm 1.35$. For motivation, the mean condom attitudes, subjective norms and behavioral intentions scores were $17.12 \pm 3.83,17.49$ \pm 4.33 and $18.00 \pm 3.40$, respectively. Regarding behavioral skills, the mean scores for perceived difficulty and effectiveness were $25.87 \pm 3.80$ and $19.76 \pm 5.67$, respectively. The frequency of condom use when having anal sex during the last 6 months was $4.09 \pm 1.19$ (Table 2).

\section{Correlations among constructs in the IMB model}

Condom use was positively associated with education, income, seeking sexual partners online, receiving HIV prevention services, personal attitudes, subjective norms, behavioral intentions, perceived difficulty, and perceived effectiveness $(p<0.01)$, and was negatively associated with depression and IPV $(p<0.01)$ (Table 3).

\section{Model estimation \\ Conventional IMB model}

In the final conventional IMB model, behavioral skills positively and directly predicted safe sex behavior (standardized path coefficient $\beta=0.382, p<0.001$ ) and partially mediated the associations between information $(\beta=0.137$, $p<0.001)$ and motivation $(\beta=0.432, p<0.001)$ and condom use (Fig. 1). All paths from the latent variable to the corresponding observed variables were statistically significant $(p<0.001)$. However, the final conventional IMB model did not fit the data ideally, with a $\chi^{2} / d f$ of 3.201 , which was not within the acceptable rang of 3 or less, although the RMSEA was $0.048<0.05$, GFI was $0.976>$ 0.90 , and AGFI was $0.945>0.90$ (Table 4). The total effect of all IMB constructs on condom use was 0.599 .

\section{Modified IMB model}

Similar to the final conventional IMB model, the final modified IMB model revealed that behavioral skills positively contributed to safe sex behavior directly $(\beta=0.385, p<0.001)$ and partially mediated the associations between information $(\beta=0.106, p=0.005)$ and motivation $(\beta=0.390, p<0.001)$ and condom use (Fig. 2). Regarding the extended associated factors, higher education $(\beta=0.124, p=0.001)$ and receiving HIV prevention services $(\beta=0.126, p<0.001)$ had a positive effect on information. Depression $(\beta=-0.171, p<0.001))$ and CSA $(\beta=-0.090, p=0.014)$ had a negative effect on motivation. Participants who were more educated $(\beta=0.112, p=0.003)$, had a higher income $(\beta=0.171, p<0.001)$, and sought sexual partners online $(\beta=0.086, p=0.027)$ were more likely to have better behavioral skills. Participants with depression $(\beta=-$ $0.263, p<0.001)$ and a history of IPV $(\beta=-0.151, p<0.001)$ were less likely to have better behavioral skills. All paths from the latent variable to the corresponding observed variables were also statistically significant $(p<0.001)$. The final modified IMB model fitted the data ideally, with a $\chi^{2} / d f$ of 2.801 , RMSEA of $0.043<0.05$, GFI of $0.980>0.90$, and AGFI of $0.960>0.90$ (Table 4). The total effect of all modified IMB constructs on condom use was 0.927 .

\section{Discussion}

The current study applied the conventional IMB model and developed a modified IMB model to predict HIV preventive behavior among Chinese MSM. The modified IMB model fitted the data better than the conventional model. The modified IMB model demonstrated that the multilevel factors, such as education, income, depression, CSA, IPV, sexual partner seeking behavior, and access to HIV prevention services, impacted condom use in addition to information, motivation, and behavioral skills.

Correct and consistent condom use is one of the most effective strategies for preventing the spread of HIV among MSM [8]. The proportion of consistent condom use among MSM was $52.05 \%$, which was slightly higher than that (47\%) reported in one previous meta-analysis in China [6]. When compared to the result of a serial cross-sectional study conducted among MSM in Guangzhou from 2008 to 2013 [7], the proportion of consistent condom use among MSM increased from 41.6 to $52.05 \%$ in 2017 , which revealed that the basic HIV control and prevention measures were making progress [44]. However, condom promotion remains a challenge due to the large MSM population and the increasing HIV prevalence among MSM [44, 45]. Moreover, one previous study presented that condom use showed no significant protection when comparing occasional use to no use among MSM having any anal sex with an HIV-positive male partner [46]. Therefore, it is important to develop an HIV prevention program for consistent condom use under the guidance of health promotion theoretical frameworks. The IMB model is one theory that effectively predicts the condom use [10-13] and guides condom promotion interventions in various populations, including MSM [14-16]. 
Table 1 Sociodemographic, sexual and psychosocial characteristics of 976 men who have sex with men in Guangzhou, China

\begin{tabular}{|c|c|c|c|}
\hline Characteristics & $N\left(\%^{a}\right)$ & Characteristic & $N\left(\%^{a}\right)$ \\
\hline Age (years) & & Sexual orientation & \\
\hline $18 \sim$ & $242(24.80)$ & Homosexual & 723(74.08) \\
\hline $24 \sim$ & $287(29.40)$ & Heterosexual & $4(0.41)$ \\
\hline $28 \sim$ & 205(21.00) & Bisexual & 208(21.31) \\
\hline $32 \sim 67$ & $242(24.80)$ & Unsure & $41(4.2)$ \\
\hline Birthplace & & Sexual role & \\
\hline Guangzhou City & $348(35.66)$ & Insertive only & 157(16.08) \\
\hline Other cities in Guangdong province & $327(33.50)$ & Receptive only & 158(16.19) \\
\hline Other provinces & $301(30.84)$ & Versatile & $661(67.73)$ \\
\hline Duration in Guangzhou(months) & & Seeking sexual partners ${ }^{c}$ & \\
\hline$<12$ & $112(11.48)$ & Internet & 878(89.96) \\
\hline$\geq 12$ & $864(88.52)$ & Non-Internet & $98(10.04)$ \\
\hline Education & & Condom use during anal sex & \\
\hline$\leq$ Middle school & $66(6.76)$ & Never & 38(3.89) \\
\hline High school or equivalent & 175(17.93) & Occasionally & 114(11.68) \\
\hline$\geq$ College & $735(75.31)$ & Sometimes & 75(7.69) \\
\hline Marital status & & Often & $241(24.69)$ \\
\hline Unmarried & 849(86.99) & Always & $508(52.05)$ \\
\hline Married/cohabitation & 104(10.66) & HIV prevention service & \\
\hline Divorced/widowed & $23(2.35)$ & Yes & $623(63.83)$ \\
\hline Monthly income (Yuan) & & No & $353(36.17)$ \\
\hline 0 & 118(12.09) & Child sexual abuse & \\
\hline $1 \sim$ & $96(9.84)$ & Yes & $263(26.95)$ \\
\hline $3001 \sim$ & $273(27.97)$ & No & 713(73.05) \\
\hline $5001 \sim$ & $320(32.79)$ & Intimate partner violence & \\
\hline$>10,000$ & 169(17.31) & Yes & $129(13.22)$ \\
\hline Occupation ${ }^{b}$ & & No & $847(86.78)$ \\
\hline Student & $146(14.96)$ & Depression & \\
\hline Employed & $777(79.61)$ & Yes & $422(43.24)$ \\
\hline Other & $52(5.33)$ & No & $554(56.76)$ \\
\hline Total & $976(100.00)$ & Total & $976(100.00)$ \\
\hline
\end{tabular}

${ }^{\mathrm{a}}$ Because of rounding, not all percentages total 100

b One case was missing occupation information. Other refers to part-time, unemployed, retired, and so on

Internet refers to websites or smart phone applications. Non-Internet refers to real places such as a bar, dance hall, public baths, and so on

According to the original IMB model proposed by Fisher [17, 18], condom use was affected primarily by information, motivation and behavioral skills. Consistent with the original IBM model, behavioral skills were important component in the current study and had a direct effect on condom use. Information and motivation did not appear to contribute to condom use directly as Fisher proposed but instead indirectly mediated behavioral skills. Nevertheless, some other studies also demonstrated that the effect of information and motivation on condom use was not significant $[23,47]$.
In the current study, $81.25 \%$ of the participants had adequate HIV-related knowledge. Only the questions "Can correct condom use reduce the risk of HIV infection and transmission" and "Should HIV consultation and testing be actively sought after high risk behaviors (needle-sharing, drug abuse, unsafe sex, etc.)" were correctly answered by 98.05 and $96.21 \%$ of the participants, respectively, which achieved the target $(90 \%)$ of having adequate HIV-related knowledge among MSM [48]. Thus, more efforts should be made to improve the gaps in HIV-related knowledge among MSM. Our results added to existing literature showing that information does not always have a 
Table 2 Mean scores of constructs of the IMB model among 976 men who have sex with men in Guangzhou, China

\begin{tabular}{lll}
\hline Construct & $\mathrm{M}^{\mathrm{a}}$ & $\mathrm{SD}^{\mathrm{b}}$ \\
\hline Information & & \\
Knowledge (0-8) & 6.59 & 1.35 \\
Motivation & & \\
Personal attitudes (4-20) & 17.49 & 4.33 \\
Subjective norms (4-20) & 17.12 & 3.83 \\
Behavioral intentions (4-20) & 18.00 & 3.40 \\
Behavioral skills & & \\
Perceived difficulty (6-30) & 25.87 & 3.80 \\
Perceived effectiveness (5-25) & 19.76 & 5.67 \\
HIV preventive behavior (Condom use: 1-5) & 4.09 & 1.19 \\
\hline
\end{tabular}

${ }^{\mathrm{a}} M$ mean

${ }^{\mathrm{b}} S D$ standard deviation

direct effect on sexual risk behavior. This lack of effect could be due to a ceiling effect, since the overall level of HIV-related knowledge was high and did not yield any additional explanatory power [23]. Moreover, previous studies suggested that adequate HIV-related knowledge appeared to be an insufficient determinant to predict condom use and change risk behavior [23, 49]. Although information did not have a direct influence on condom use, information indirectly contributed to condom use mediated by behavioral skills, and remained a necessary component of HIV prevention interventions, which was consistent with previous studies [11, 20].

Motivation also indirectly contributed to condom use mediated by behavioral skills. Individuals with a positive personal attitude towards condom use and higher subjective norms and intentions regarding condom use were more likely to show more positive motivation to use condoms [12, $13,20]$. It is easy to understand the relationship between a positive attitude and condom use. The subjective norm represented the perceptions of social referents and motivation to comply, which could affect HIV prevention intentions and behaviors [11, 12, 17, 20]. However, previous studies suggested that motivation had a direct effect on condom use among male street laborers [20] and STI clinic patients [12]. Behavioral skills contributed to condom use directly, which revealed that individuals who displayed better skills in preparation, negotiation and practice were more likely to engage in HIV prevention behavior [20]. The current study placed behavioral skills in the role as a mediating factor for all components of the model, which was consistent with some previous studies $[12,20]$ but inconsistent with other studies $[11,24]$.

The conventional IMB model focused only on individuallevel factors that influenced condom use, and did not fit the data ideally in the current study. According to some multilevel models, the HIV risk and AIDS care behaviors are influenced by multilevel factors at different ecological levels [26-30]. One comprehensive and practical review recommended that multilevel approaches for HIV-related behavior changes could serve as the basis for extending the conventional IMB model with multilevel factors [30]. Beyond individual-level factors, the modified IMB model integrated interpersonal/network-level and structural-level factors to fit the data ideally. Moreover, the total effect of the modified IMB model (0.927) on condom use was much larger than that of the non-extended IMB model (0.599). Therefore, this

Table 3 Pearson's correlation between constructs of the modified IMB model among 976 men who have sex with men in Guangzhou, China

\begin{tabular}{|c|c|c|c|c|c|c|c|c|c|c|c|c|c|c|c|}
\hline No. & Construct & 1 & 2 & 3 & 4 & 5 & 6 & 7 & 8 & 9 & 10 & 11 & 12 & 13 & 14 \\
\hline 1 & Education & 1 & & & & & & & & & & & & & \\
\hline 2 & Income & $0.24^{* * *}$ & 1 & & & & & & & & & & & & \\
\hline 3 & $\begin{array}{l}\text { Sexual partner seeking } \\
\text { behavior }\end{array}$ & $0.14^{* * *}$ & 0.06 & 1 & & & & & & & & & & & \\
\hline 4 & Depression & $-0.14^{* * *}$ & $-\overline{0}^{* 13^{* * *}}$ & -0.06 & 1 & & & & & & & & & & \\
\hline 5 & Intimate partner violence & -0.05 & -0.03 & $-\overline{0}^{* 1 * *}$ & $0.09^{* *}$ & 1 & & & & & & & & & \\
\hline 6 & Child sexual abuse & $-0.10^{* *}$ & $-0.09^{* *}$ & -0.06 & $0.13^{* * *}$ & $0.13^{* * *}$ & 1 & & & & & & & & \\
\hline 7 & HIV prevention services & $0.10^{* *}$ & 0.01 & 0.02 & $-0.09^{* *}$ & 0.02 & 0.01 & 1 & & & & & & & \\
\hline 8 & Information & $0.09^{* *}$ & $0.07^{*}$ & 0.04 & $-0.06^{*}$ & 0.04 & -0.01 & $0.09^{* *}$ & 1 & & & & & & \\
\hline 9 & Personal attitudes & $0.20^{* * *}$ & $0.12^{* * *}$ & $0.07^{*}$ & $-0.19^{* * *}$ & -0.04 & $-0.08^{*}$ & 0.01 & $0.12^{* * *}$ & 1 & & & & & \\
\hline 10 & Subjective norms & $0.09^{* *}$ & 0.02 & -0.03 & $-0.13^{* * *}$ & -0.05 & -0.03 & 0.02 & 0.04 & $0.57^{* * *}$ & 1 & & & & \\
\hline 11 & Behavioral intentions & $0.16^{* * *}$ & $0.10^{* *}$ & 0.02 & $-0.13^{* * *}$ & 0.01 & -0.05 & 0.01 & $0.10^{* * *}$ & $0.64^{* * *}$ & $0.65^{* * *}$ & 1 & & & \\
\hline 12 & Perceived difficulty & $0.19^{* * *}$ & $0.19^{* * *}$ & 0.06 & $-0.23^{* * *}$ & $-0.11^{* * *}$ & -0.05 & $0.13^{* * *}$ & $0.09^{* *}$ & $0.41^{* * *}$ & $0.41^{* * *}$ & $0.44^{* * *}$ & 1 & & \\
\hline 13 & Perceived effectiveness & $0.12^{* *}$ & $0.14^{* *}$ & $0.16^{* * *}$ & $-0.32^{* * *}$ & $-0.07^{*}$ & $-0.15^{* * *}$ & $0.09^{* *}$ & $0.11^{* *}$ & $0.24^{* * *}$ & $0.18^{* * *}$ & $0.25^{* * *}$ & $0.37^{* * *}$ & 1 & \\
\hline 14 & Condom use & $0.17^{* * *}$ & $0.13^{* * *}$ & $0.10^{* *}$ & $-0.12^{* * *}$ & $-0.09^{* *}$ & -0.05 & $0.09^{* *}$ & 0.05 & $0.18^{* * *}$ & $0.15^{* * *}$ & $0.14^{* * *}$ & $0.29^{* * *}$ & $0.32^{* * *}$ & 1 \\
\hline
\end{tabular}



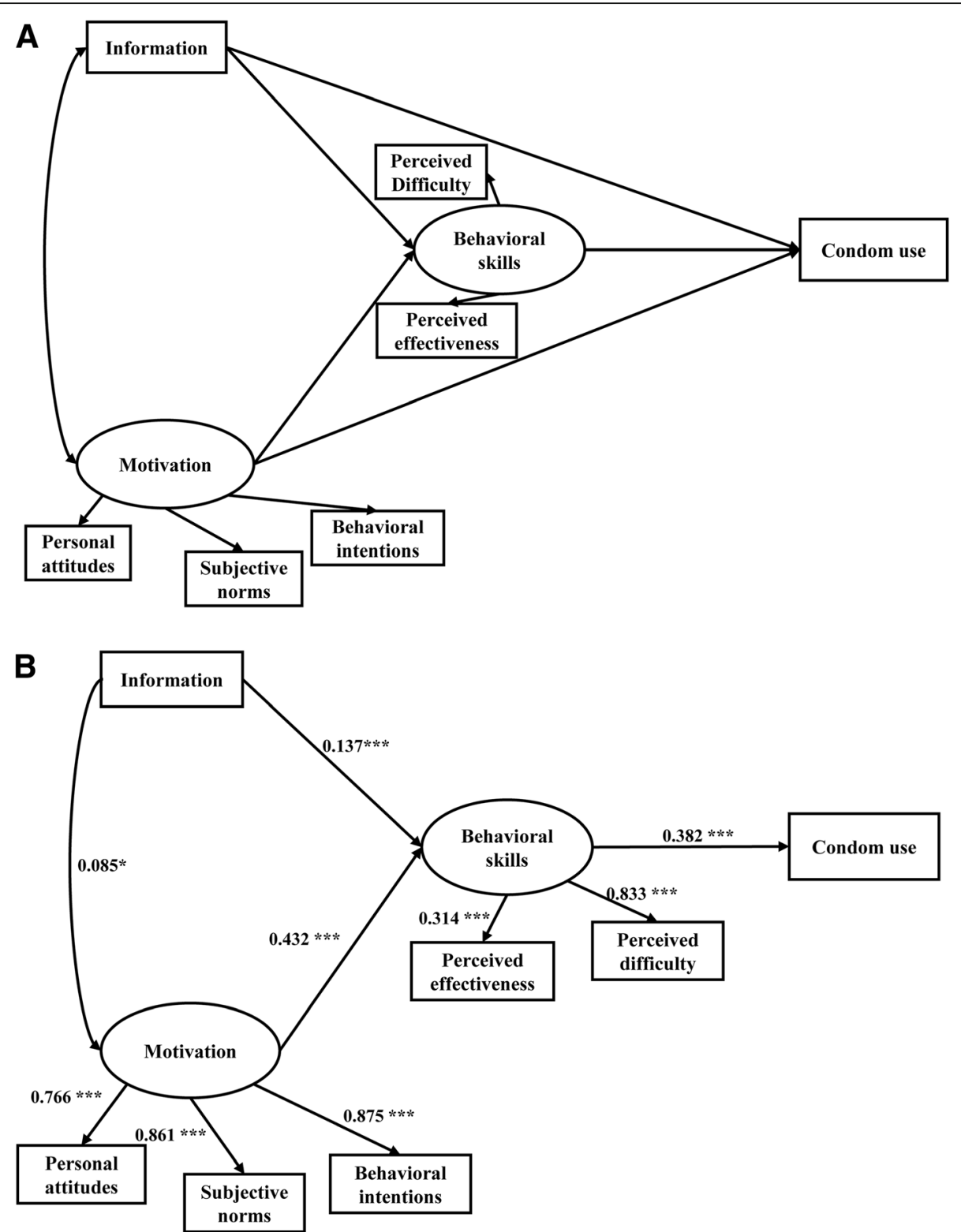

Fig. 1 The initial and final conventional IMB models with standardized path coefficients among 976 men who have sex with men in Guangzhou, China. a: The initial conventional IMB model. b: The final conventional IMB model. ${ }^{*} P<0.05,{ }^{* *} P<0.01,{ }^{* * *} P<0.001$

Table 4 The model fit of the conventional and modified IMB models among 976 men who have sex with men in

\begin{tabular}{llll}
\multicolumn{3}{l}{ Guangzhou, China } \\
\hline Index & Criterion & Conventional IMB & Modified IMB \\
\hline$X^{2} / d f^{\text {a }}$ & $<5.00$ & 3.201 & 2.801 \\
RMSEA & $<0.05$ & 0.048 & 0.043 \\
GFI & $>0.90$ & 0.976 & 0.98 \\
AGFI & $>0.90$ & 0.945 & 0.96
\end{tabular}

${ }^{a} x^{2} / d f: X^{2}$ and degree of freedom ratio; RMSEA: root mean square error of approximation; GFI: goodness of fit index; AGFI: adjusted goodness of fit index modified IMB model with multilevel factors was suggested for use as a theoretical framework to guide the behavior interventions and improve the condom use among MSM in China.

The results of the final modified IMB model showed that more educated individuals had more adequate HIV prevention and transmission information [50], which contributed to condom use [32]. However, another study showed that in one personal resource construct, education did not have an impact on information or behavioral skills [23]. Low-income individuals may be more likely to encounter stressors and/or limit their access to resources to buffer against these stressors [51]. Individuals with socioeconomic disadvantages 

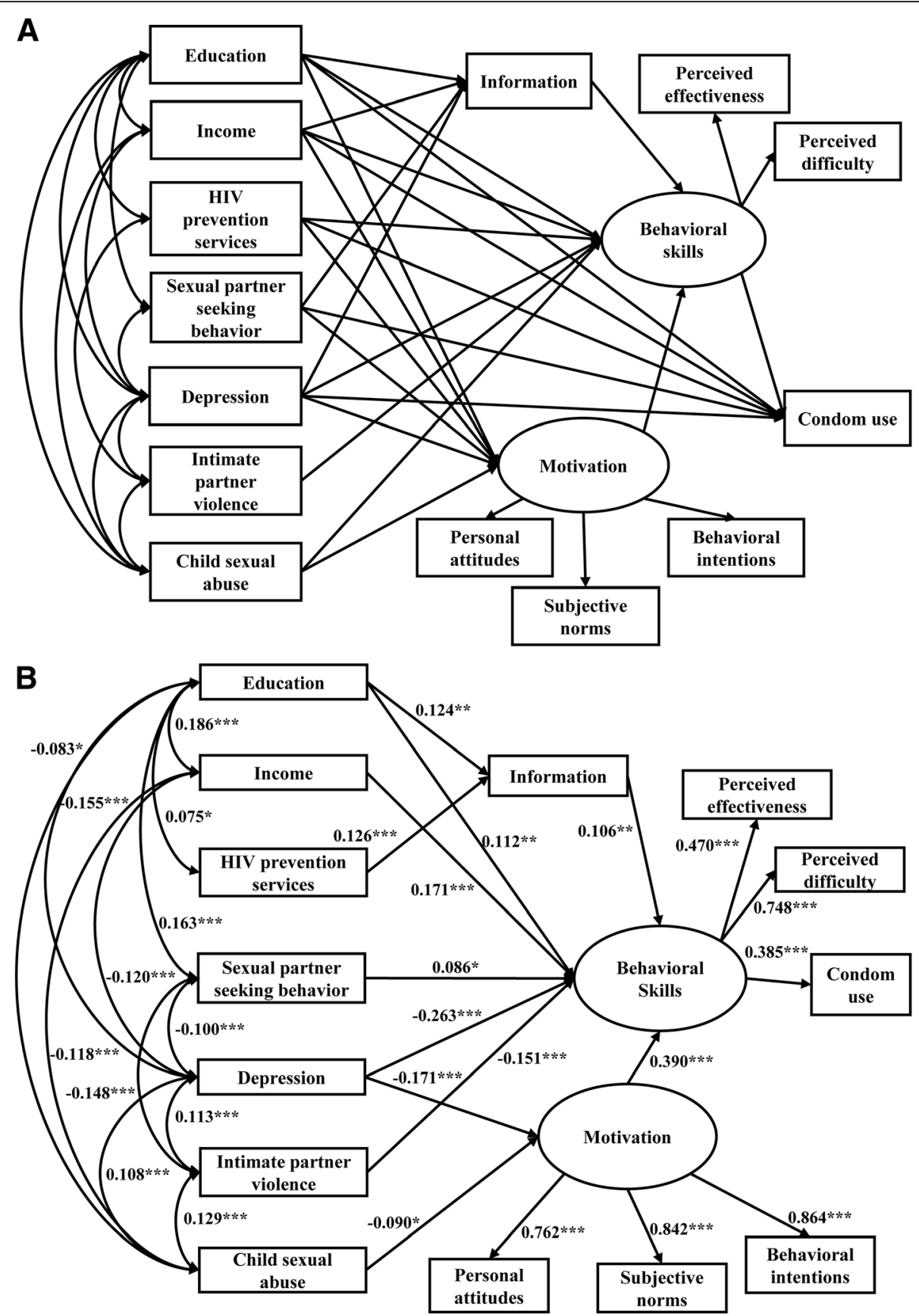

Fig. 2 The initial and final modified IMB models with standardized path coefficients among 976 men who have sex with men in Guangzhou, China. a: The initial modified IMB model. b: The final modified IMB model. ${ }^{*} P<0.05,{ }^{* *} P<0.01,{ }^{* *} P<0.001$

utilize their limited cognitive coping resources in dealing with these excess stressors, especially lack of social support, leading to engagement in condomless sexual behaviors [31]. One modified IMB model suggested that depressed MSM were more likely to have sexual risk behaviors to mitigate distress, which might further compromise motivation for behavior changes [23]. Another modified IMB model presented that the latent variable "psychosocial factors", including depression as one of the five constructs, was negatively associated with behavioral skills [20], which was consistent with the current results.

CSA and IPV had negative effects on condom use, with the former mediated by motivation and the latter by behavioral skills. Individuals with a CSA experience might foster problematic coping styles and relational instability, resulting in greater exposure to risk opportunities and their condom use decisions were more likely to be affected by their partner's reaction [52]. They were more likely to think condoms 
interfered with sexual pleasure and less likely to think condoms were important [53], which was consistent with the negative association between CSA and motivation in the current study. Previous studies suggested that individuals who had experienced IPV were significantly less likely to report having felt able to negotiate condom use [54, 55], which was consistent with the negative association between IPV and behavioral skills in the current study.

Due to technological advances, MSM have multiple platforms for online sex seeking, such as gay-specific forums, chat rooms, and dating websites [56]. Previous studies presented that condom use self-efficacy, which referred to condom acquisition, proper condom use, and negotiation skills, played an important role in condom use behavior among MSM. Higher rates of condom use self-efficacy were associated with lower rates of risky sexual practices [57-59]. The good behavioral skills among the MSM who sought sexual partners online in the current study might be attributed to high condom use self-efficacy among these participants [53]. However, whether seeking sex partners online or offline increases condom use remains controversial. Some previous studies indicated that partners sought online could increase the risk of UAI $[35,60]$, whereas other studies believed that no difference in UAI existed between gay app users and non-app users [56, 61]. Nevertheless, the fact that most (89.96\%) of the participants sought homosexual partners online and that $46.81 \%$ of the MSM reported UAI in the current study suggested that websites and gay apps were both risk environments and that Internet-based behavioral interventions were necessary. HIV prevention services provided adequate HIV prevention and transmission knowledge and thus had a positive effect on information that indirectly resulted in condom use. However, a gap existed between the target of more than $90 \%$ coverage of HIV prevention services [48] and the fact that only approximately two-thirds (63.83\%) of the MSM received HIV prevention services. Therefore, more efforts should be made to expand the coverage of HIV prevention services among MSM in China.

Despite these strengths, several limitations should be noted when interpreting and generalizing the results. First, causal inference remained ambiguous due to the cross-sectional nature of this study [12]. Thus, prospective studies are called for to further confirm the effects of the modified IMB model components on HIV-preventive behavior. Second, the convenience sampling approach may limit the generalizability [23]. Nevertheless, the six VCT clinics and the two popular community-based HIV service centers, which covered 8 of the 11 districts in Guangzhou, are believed to have provided a relatively adequate representative sample. The birthplaces of the participants in Guangzhou, other cities in Guangdong province, and other provinces each accounted for approximately one-third of the participants, which might extend the generalizability of the current study. Third, only Cronbach's alpha was used to assess the reliability of the scale items. More forms of reliability and validity assessment, such as test-retest reliability, and discriminate validity should be conducted in future studies. Finally, the validity of self-reported data should be taken into consideration in any study of sexual behavior. However, an anonymous electronic questionnaire was administered to remove such barriers to participation in this survey $[23,62]$.

\section{Conclusion}

Our results stressed the need to pay more attention to the relatively lower proportion of consistent condom use among MSM in the current study. Thus, targeted intervention for safe sex should be created. The modified IMB model fitted the data ideally and could serve as a theoretical framework of behavioral interventions for safe sex. According to the final modified IMB model developed in this study, interventions to increase condom use among MSM should prioritize reducing depression level and increasing HIV-related information, motivation, behavioral skills, and access to HIV prevention services by targeting those with lower education levels and incomes, those who have experienced CSA and IPV, and those who seek sexual partners offline. As components of the modified IMB model, the changeable factors can be targeted to improve the effectiveness of the behavioral intervention programs. Nevertheless, further prospective studies are needed to examine the predictive power of the modified IMB model. Furthermore, behavioral intervention programs with a multilevel approach under guideline of the modified IMB model are encouraged to improve consistent condom use among MSM.

\section{Additional file}

Additional file 1: Questionnaire for Modified IMB Model. (DOC 187 kb)

\section{Abbreviations}

AGFI: adjusted goodness of fit index; AIDS: acquired immune deficiency syndrome; ART: antiretroviral therapy; CDC: Centers for Disease Control and Prevention; CSA: child sexual abuse; GFI: goodness of fit index; HIV: human immunodeficiency virus; IMB: Information-Motivation-Behavioral skills; IPV: intimate partner violence; M: mean; MSM: men who have sex with men; RMSEA: root mean square error of approximation; SD: standard deviation;

SDS: self-rating depression scale; STI: sexually transmitted infection; UAl: unprotected anal intercourse; VCT: voluntary counseling testing; WLS: weighted least squares

\section{Acknowledgements}

The authors would like to thank the staff in the six district CDCs of Guangzhou (Baiyun, Conghua, Panyu, Huadu, Huangpu, and Zengcheng District), and two community- based HIV service centers (Lingnan Partners and Zhitong Charity) for their help with data acquisition in this study.

\section{Funding}

This study was funded by the "13th Five-Year" plan for the development of philosophy and social sciences in Guangzhou (2018GZGJ67) from the Guangzhou Association of Social Science Societies (http://www.gzsk.org.cn/), the Special Funds for Provincial Health and Family Planning Development of 
Guangdong in China in 2016 (AIDS prevention project: 2100409) from Department of Finance of Guangdong Province (http://czt.gd.gov.cn/), and the Young Scientists Fund (81703282) from the National Natural Science Foundation of China (http://www.nsfc.gov.cn/). The funding bodies had no role of in the design of the study and collection, analysis, and interpretation of data and writing of the manuscript.

\section{Availability of data and materials}

All data generated or analyzed during this study are included in this published article.

\section{Authors' contributions}

$H J, W C$, and YY conceived and designed the study; XC, JL and ZT acquired, analyzed, or interpreted data; $\mathrm{HJ}$ drafted the manuscript; WC critically revised the manuscript for important intellectual content; $X C$ performed the statistical analysis; $\mathrm{HJ}$ obtained funding; and $Y Y$ supervised the study. All authors read and approved the final manuscript.

\section{Ethics approval and consent to participate}

This study was approved by the Ethics Committee of Guangdong Pharmaceutical University. All the study participants signed a written informed consent document after comprehending the objectives and procedures of the study.

\section{Consent for publication}

Not applicable.

\section{Competing interests}

The authors declare that they have no competing interests.

\section{Publisher's Note}

Springer Nature remains neutral with regard to jurisdictional claims in published maps and institutional affiliations.

Received: 4 October 2018 Accepted: 25 February 2019

Published online: 04 March 2019

\section{References}

1. Collaborators GH. Estimates of global, regional, and national incidence, prevalence, and mortality of HIV, 1980-2015: the global burden of disease study 2015. The lancet HIV. 2016;3(8):e361-87.

2. Beyrer C, Baral SD, Collins C, Richardson ET, Sullivan PS, Sanchez J, Trapence G, Katabira E, Kazatchkine M, Ryan O, et al. The global response to HIV in men who have sex with men. Lancet. 2016;388(10040):198-206.

3. National Health and Family Planning Commission of the People's Republic of China: 2015 China AIDS Response Progress Report (2015). Available from: http://www.unaids.org/sites/default/files/country/documents/CHN_ narrative_report_2015.pdf. Accessed 13 June 2018.

4. Xu JJ, Tang WM, Zou HC, Mahapatra T, Hu QH, Fu GF, Wang Z, Lu L, Zhuang MH, Chen X, et al. High HIV incidence epidemic among men who have sex with men in China: results from a multi-site cross-sectional study. Infect Dis Poverty. 2016;5(1):82.

5. Beyrer C, Baral SD, van Griensven F, Goodreau SM, Chariyalertsak S, Wirtz AL, Brookmeyer R. Global epidemiology of HIV infection in men who have sex with men. Lancet. 2012;380(9839):367-77.

6. Wu J, Hu Y, Jia Y, Su Y, Cui H, Liu H, Wang N. Prevalence of unprotected anal intercourse among men who have sex with men in China: an updated meta-analysis. PLoS One. 2014;9(5):e98366.

7. Cheng W, Tang W, Zhong F, Babu GR, Han Z, Qin F, Gao K, Mai H, Zhao Y, Liang $\mathrm{C}$, et al. Consistently high unprotected anal intercourse (UAI) and factors correlated with UAl among men who have sex with men: implication of a serial cross-sectional study in Guangzhou, China. BMC Infect Dis. 2014;14:696.

8. Moreno R, Nababan HY, Ota E, Wariki WM, Ezoe S, Gilmour S, Shibuya K. Structural and community-level interventions for increasing condom use to prevent the transmission of HIV and other sexually transmitted infections. Cochrane Database Syst Rev. 2014;7:CD003363.

9. Glanz K, Bishop DB. The role of behavioral science theory in development and implementation of public health interventions. Annu Rev Public Health. 2010;31:399-418.
10. Kalichman SC, Picciano JF, Roffman RA. Motivation to reduce HIV risk behaviors in the context of the information, motivation and behavioral skills (IMB) model of HIV prevention. J Health Psychol. 2008;13(5):680-9.

11. Zhang H, Liao M, Nie X, Pan R, Wang C, Ruan S, Zhang C, Tao X, Kang D, Jiang B. Predictors of consistent condom use based on the informationmotivation-behavioral skills (IMB) model among female sex workers in Jinan, China. BMC Public Health. 2011;11:113.

12. John SA, Walsh JL, Weinhardt LS. The information-motivation-behavioral skills model revisited: a network-perspective structural equation model within a public sexually transmitted infection clinic sample of hazardous alcohol users. AIDS Behav. 2017;21(4):1208-18.

13. Cai $Y$, Ye X, Shi R, Xu G, Shen L, Ren J, Huang H. Predictors of consistent condom use based on the information-motivation-behavior skill (IMB) model among senior high school students in three coastal cities in China. BMC Infect Dis. 2013;13:262.

14. Ybarra ML, Liu W, Prescott TL, Phillips G 2nd, Mustanski B. The Effect of a Text Messaging Based HIV Prevention Program on Sexual Minority Male Youths: A National Evaluation of Information, Motivation and Behavioral Skills in a Randomized Controlled Trial of Guy2Guy. AIDS Behav. 2018;10:1-10.

15. Fisher JD, Cornman DH, Shuper PA, Christie S, Pillay S, Macdonald S, Ngcobo N, Amico KR, Lalloo U, Friedland G, et al. HIV prevention counseling intervention delivered during routine clinical care reduces HIV risk behavior in HIV-infected south Africans receiving antiretroviral therapy: the Izindlela Zokuphila/options for health randomized trial. J Acquir Immune Defic Syndr. 2014;67(5):499-507.

16. Sun WH, Wong CKH, Wong WCW. A peer-led, social media-delivered, safer sex intervention for Chinese college students: randomized controlled trial. J Med Internet Res. 2017;19(8):e284.

17. Fisher JD, Fisher WA. Changing AIDS-risk behavior. Psychol Bull. 1992;111(3):455-74.

18. Fisher JD, Fisher WA, Williams SS, Malloy TE. Empirical tests of an information-motivation-behavioral skills model of AIDS-preventive behavior with gay men and heterosexual university students. Health Psychol. 1994; 13(3):238-50.

19. Misovich Steven J FWA, Fisher Jeffrey D: A measure of AIDS prevention information, motivation, behavioral skills, and behavior, In CM Davis, WH Yarber, R Bauserman, G Schreer, SL Davis (Eds.), Handbook of Sexuality Related Measures. SAGE publishing, 1998. pp. 328-337.

20. Van Huy N, PDunne M, Debattista J. Predictors of condom use behaviour among male street labourers in urban Vietnam using a modified informationmotivation-behavioral skills (IMB) model. Cult Health Sex. 2016;18(3):321-36.

21. Yang X, Xia G, Li X, Latkin C, Celentano D. Social influence and individual risk factors of HIV unsafe sex among female entertainment workers in China. AIDS Educ Prev. 2010;22(1):69-86.

22. Johnson BT, Scott-Sheldon LA, Carey MP. Meta-synthesis of health behavior change meta-analyses. Am J Public Health. 2010;100(11):2193-8.

23. Nostlinger C, Niderost S, Platteau T, Muller MC, Stanekova D, Gredig D, Roulin C, Rickenbach M, Colebunders R, Swiss HIVCS, et al. Sexual protection behavior in HIV-positive gay men: testing a modified informationmotivation-behavioral skills model. Arch Sex Behav. 2011;40(4):817-27.

24. Niderost S, Gredig D, Roulin C, Rickenbach M, Swiss Hiv cohort S, Eurosupport 5 study G. Predictors of HIV-protection behaviour in HIVpositive men who have sex with casual male partners: a test of the explanatory power of an extended information-motivation-Behavioural skills model. AIDS Care. 2011;23(7):908-19.

25. Salazar LF, Bradley EL, Younge SN, Daluga NA, Crosby RA, Lang DL, DiClemente RJ. Applying ecological perspectives to adolescent sexual health in the United States: rhetoric or reality? Health Educ Res. 2010;25(4):552-62.

26. Zimmerman RS, Noar SM, Feist-Price S, Dekthar O, Cupp PK, Anderman E, Lock S. Longitudinal test of a multiple domain model of adolescent condom use. J Sex Res. 2007;44(4):380-94.

27. Johnson BT, Redding CA, DiClemente RJ, Mustanski BS, Dodge B, Sheeran P, Warren MR, Zimmerman RS, Fisher WA, Conner MT, et al. A network-individualresource model for HIV prevention. AIDS Behav. 2010;14(Suppl 2):204-21.

28. Latkin C, Weeks MR, Glasman L, Galletly C, Albarracin D. A dynamic social systems model for considering structural factors in HIV prevention and detection. AIDS Behav. 2010;14(Suppl 2):222-38.

29. Friedman SR, Downing MJ Jr, Smyrnov P, Nikolopoulos G, Schneider JA, Livak B, Magiorkinis G, Slobodianyk L, Vasylyeva T1, Paraskevis D, et al. Socially-integrated transdisciplinary HIV prevention. AIDS Behav. 2014;18(10):1821-34.

30. Kaufman MR, Cornish F, Zimmerman RS, Johnson BT. Health behavior change models for HIV prevention and AIDS care: practical 
recommendations for a multi-level approach. J Acquir Immune Defic Syndr. 2014:66(Suppl 3):S250-8.

31. Ayala G, Bingham T, Kim J, Wheeler DP, Millett GA. Modeling the impact of social discrimination and financial hardship on the sexual risk of HIV among Latino and black men who have sex with men. Am J Public Health. 2012; 102(Suppl 2):S242-9.

32. Wang Y, Wang Z, Jia M, Liang A, Yuan D, Sun Z, Gan F, Wang Y, Cai Y, Zhang Z. Association between a syndemic of psychosocial problems and unprotected anal intercourse among men who have sex with men in Shanghai, China. BMC Infect Dis. 2017;17(1):46.

33. Williams JK, Wilton L, Magnus M, Wang L, Wang J, Dyer TP, Koblin BA, Hucks-Ortiz C, Fields SD, Shoptaw S, et al. Relation of childhood sexual abuse, intimate partner violence, and depression to risk factors for HIV among black men who have sex with men in 6 US cities. Am J Public Health. 2015;105(12):2473-81

34. Dunkle KL, Wong FY, Nehl E, Lin L, He N, Huang J, Zheng T. Male-on-male intimate partner violence and sexual risk behaviors among money boys and other men who have sex with men in Shanghai, China. Sex Transm Dis. 2013;40(5):362-5.

35. Lewnard JA, Berrang-Ford L. Internet-based partner selection and risk for unprotected anal intercourse in sexual encounters among men who have sex with men: a meta-analysis of observational studies. Sex Transm Infect. 2014;90(4):290-6.

36. Ramanathan S, Chakrapani V, Ramakrishnan L, Goswami P, Yadav D, Subramanian T, George B, Paranjape R. Consistent condom use with regular, paying, and casual male partners and associated factors among men who have sex with men in Tamil Nadu, India: findings from an assessment of a large-scale HIV prevention program. BMC Public Health. 2013;13:827.

37. Salganik MJ. Variance estimation, design effects, and sample size calculations for respondent-driven sampling. J Urban Health. 2006;83(6 Suppl):i98-112.

38. Zung WW. A self-rating depression scale. Arch Gen Psychiatry. 1965;12:63-70.

39. Dai W, Luo Z, Xu R, Zhao G, Tu D, Yang L, Wang F, Cai Y, Lan L, Hong F, et al. Prevalence of HIV and syphilis co-infection and associated factors among non-commercial men who have sex with men attending a sexually transmitted disease clinic in Shenzhen, China. BMC Infect Dis. 2017;17(1):86.

40. Olsson UH, Foss T, Troye SV, Howell RD. The performance of ML, GLS, and WLS estimation in structural equation modeling under conditions of misspecification and nonnormality. Struct Equ Model Multidiscip J. 2009;7(4):557-95.

41. McDonald RP, Ho MH. Principles and practice in reporting structural equation analyses. Psychol Methods. 2002;7(1):64-82.

42. Byrne B. Structural equation modeling with AMOS: basic concepts, applications, and programming. New York: Routledge; 2009.

43. Hu LT, Bentler PM. Cut-off criteria for fit indexes in covariance structure analysis: conventional criteria versus new alternatives. Struct Equ Model A Multidiscip J. 1999;6(1):1-55.

44. Cheng W, Cai Y, Tang W, Zhong F, Meng G, Gu J, Hao C, Han Z, Li J, Das A, et al. Providing HIV-related services in China for men who have sex with men. Bull World Health Organ. 2016;94(3):222-7.

45. Zhong F, Liang B, Xu H, Cheng W, Fan L, Han Z, Liang C, Gao K, Mai H, Qin $F$, et al. Increasing HIV and decreasing syphilis prevalence in a context of persistently high unprotected anal intercourse, six consecutive annual surveys among men who have sex with men in Guangzhou, China, 2008 to 2013. PLoS One. 2014;9(7):e103136.

46. Smith DK, Herbst JH, Zhang X, Rose CE. Condom effectiveness for HIV prevention by consistency of use among men who have sex with men in the United States. J Acquir Immune Defic Syndr. 2015;68(3):337-44.

47. Harman JJ, Amico KR. The relationship-oriented information-motivationbehavioral skills model: a multilevel structural equation model among dyads. AIDS Behav. 2009;13(2):173-84.

48. Sun X, Lu F, Wu Z, Poundstone K, Zeng G, Xu P, Zhang D, Liu K, Liau A. Evolution of information-driven HIV/AIDS policies in China. Int J Epidemiol. 2010;39(Suppl 2):ii4-13.

49. Cornman DH, Schmiege SJ, Bryan A, Benziger TJ, Fisher JD. An informationmotivation-behavioral skills (IMB) model-based HIV prevention intervention for truck drivers in India. Soc Sci Med. 2007;64(8):1572-84.

50. Liu S, Wang K, Yao S, Guo X, Liu Y, Wang B. Knowledge and risk behaviors related to HIV/AIDS, and their association with information resource among men who have sex with men in Heilongjiang province, China. BMC Public Health. 2010;10:250.

51. Duncan DT, Park SH, Schneider JA, Al-Ajlouni YA, Goedel WC, Elbel B, Morganstein JG, Ransome Y, Mayer KH. Financial hardship, Condomless anal intercourse and HIV risk among men who have sex with men. AIDS Behav. 2017;21(12):3478-85.

52. George WH, Davis KC, Masters NT, Kajumulo KF, Stappenbeck CA, Norris J, Heiman JR, Staples JM. Partner pressure, victimization history, and alcohol: Women's condom-decision abdication mediated by mood and anticipated negative partner reaction. AIDS Behav. 2016;20(Suppl 1):S134-46.

53. Hall T, Hogben M, Carlton AL, Liddon N, Koumans EH. Attitudes toward using condoms and condom use: difference between sexually abused and nonabused African American female adolescents. Behav Med. 2008;34(2):45-54.

54. Stephenson R, Freeland R, Finneran C. Intimate partner violence and condom negotiation efficacy among gay and bisexual men in Atlanta. Sex Health. 2016.

55. Peasant C, Sullivan TP, Ritchwood TD, Parra GR, Weiss NH, Meyer JP, Murphy JG. Words can hurt: the effects of physical and psychological partner violence on condom negotiation and condom use among young women. Women Health. 2018:58(5):483-97.

56. Cao B, Liu C, Stein G, Tang W, Best J, Zhang Y, Yang B, Huang S, Wei C, Tucker JD. Faster and riskier? Online context of sex seeking among men who have sex with men in China. Sex Transm Dis. 2017;44(4):239-44.

57. Klein $\mathrm{H}$. Condom use self-efficacy and HIV risk practices among men who use the internet to find male partners for unprotected sex. Am J Mens Health. 2014;8(3):190-204.

58. Li H, Xue L, Tucker JD, Wei C, Durvasula M, Hu W, Kang D, Liao M, Tang W, Ma W. Condom use peer norms and self-efficacy as mediators between community engagement and condom use among Chinese men who have sex with men. BMC Public Health. 2017;17(1):641.

59. Safren SA, Blashill AJ, Lee JS, O'Cleirigh C, Tomassili J, Biello KB, Mimiaga MJ, Mayer KH. Condom-use self-efficacy as a mediator between syndemics and condomless sex in men who have sex with men (MSM). Health Psychol. 2018.

60. Zou H, Fan S. Characteristics of men who have sex with men who use smartphone geosocial networking applications and implications for HIV interventions: a systematic review and meta-analysis. Arch Sex Behav. 2017; 46(4):885-94.

61. Bien CH, Best JM, Muessig KE, Wei C, Han L, Tucker JD. Gay apps for seeking sex Partners in China: implications for MSM sexual health. AIDS Behav. 2015;19(6):941-6.

62. Walsh JL, Senn TE, Scott-Sheldon LA, Vanable PA, Carey MP. Predicting condom use using the information-motivation-behavioral skills (IMB) model: a multivariate latent growth curve analysis. Ann Behav Med. 2011;42(2):235-44.
Ready to submit your research? Choose BMC and benefit from:
- fast, convenient online submission
- thorough peer review by experienced researchers in your field
- rapid publication on acceptance
- support for research data, including large and complex data types
- gold Open Access which fosters wider collaboration and increased citations
- maximum visibility for your research: over $100 \mathrm{M}$ website views per year
At $\mathrm{BMC}$, research is always in progress.
Learn more biomedcentral.com/submissions 